Revista Brasileira de Informática na Educação - RBIE Brazilian Journal of Computers in Education (ISSN online: 2317-6121; print: 1414-5685) http://br-ie.org/pub/index.php/rbie

$\begin{array}{llll}\text { Submission: 09/08/2020; } & 1^{\text {st }} \text { round notif.: 13/10/2020; } & \text { New version: 27/10/2020; } & 2^{\text {nd }} \text { round notif.: 09/11/2020; } \\ \text { Camera ready: 11/11/2020; } & \text { Edition review: 14/12/2020; } & \text { Available online: 14/12/2020; } & \text { Published: 14/12/2020; }\end{array}$

\title{
Emergency Remote Computer Science Education in Brazil during the Covid-19 Pandemic: Impacts and Strategies
}

\author{
William Simão de Deus \\ Universidade de São Paulo \\ williamsimao@usp.br \\ Camila Dias de Oliveira \\ Universidade de São Paulo \\ camila_oliveira@usp.br
}

\author{
Maria Lydia Fioravanti \\ Universidade de São Paulo \\ mlfioravanti@usp.br \\ Ellen Francine Barbosa \\ Universidade de São Paulo \\ francine@icmc.usp.br
}

\begin{abstract}
At the end of 2019, there was an outbreak of pneumonia in Chinese territory that quickly spread across the globe. Due to its infection characteristics, several face-to-face activities that brought many people together had to be rethought. In this critical scenario, teaching was abruptly changed into a modality called Emergency Remote Education (ERE). Thus, many professors had to adapt materials and resources from traditional teaching to the ERE modality without any previous planning and organization. The main goal of this study is to present how ERE has been conducted by professors in the field of Computer Science in Brazil. To achieve this goal, we prepared an electronic questionnaire, which was answered by 137 professors from 69 Brazilian educational institutions. The main results achieved by this research include the impacts observed and the strategies that have been practiced by such professionals. In short, we identified that ERE provided a rupture in Computer Science Education, as the lack of pedagogical strategy and absence of remote learning experience. Many of the problems are the result of the pandemic, but the lack of efficient crisis management by political entities and the social inequality made ERE more challenging for CS professors in Brazil.
\end{abstract}

Keywords: Emergency Remote Education; Computer Science Education; Covid-19.

\begin{abstract}
Resumo
No final do ano de 2019, ocorreu o surto de uma pneumonia no território chinês, que rapidamente se espalhou por todo o globo. Devido às suas características de infecção, diversas atividades presenciais que aglomeravam pessoas tiveram de ser repensadas. Neste cenário crítico, o ensino foi transformado para uma modalidade denominada Ensino Remoto Emergencial (ERE). Nela, muitos professores tiveram de adequar materiais e recursos do ensino tradicional para o ERE sem nenhum planejamento prévio e organização. Considerando isso, o objetivo deste artigo é apresentar como o ERE vem sendo conduzido pelos professores da área de Ciência da Computação no Brasil. Para atingir este objetivo, foi elaborado um questionário eletrônico, que foi respondido por 137 professores de 69 instituições de ensino brasileiras. Os principais resultados alcançados por esta pesquisa abrangem os impactos observados e as estratégias que vêm sendo praticadas por tais profissionais. Em resumo, foi possível observar que o ERE proporcionou uma ruptura no ensino de Ciência da Computação, como a falta de estratégia pedagógica e a ausência de experiência no ensino remoto. Muitos dos problemas são decorrentes da pandemia, mas a falta de uma gestão eficiente da crise por parte das entidades políticas aliada a desigualdade social, tornou o ERE mais desafiante para os professores de Ciência da Computação no Brasil.
\end{abstract}

Palavras-chave: Ensino Remoto Emergencial; Ensino de Ciência da Computação; Covid-19.

Cite as: Deus, W. S.; Fioravanti, M. L.; Oliveira, C. D. \& Barbosa, E. F. (2020). Emergency Remote Computer Science Education in Brazil during the Covid-19 Pandemic: Impacts and Strategies. Brazilian Journal of Computers in Education (Revista Brasileira de Informática na Educação - RBIE), 28, 1032-1059. DOI: 10.5753/RBIE.2020.28.0.1032. 


\section{Introduction}

The outbreak of pneumonia with an unknown cause in Wuhan, China, was reported by the Chinese health authorities in late 2019 (Ciotti et al., 2019). The scenario quickly spread and on January 30th, 2020, the World Health Organization declared a public health emergency of international interest, presenting a high risk for countries with vulnerable health systems (Sohrabi et al., 2020). Currently, it is known that the outbreak was caused by a new type of coronavirus, named SARSCoV-2, and that the disease caused by it, denoted as Covid-19, has become one of the biggest pandemics of recent times (Arruda, 2020). Due to its transmission characteristics, as a preventive measure for the spread of the disease, it is recommended there be social distancing among people.

Thus, the social distancing imposed by Covid-19 has immediately reached different layers of society and caused several changes, especially in educational systems. According to Triyason, Tassanaviboon, and Kanthamanon (2020), such systems were strongly affected; schools and universities had to abruptly interrupt traditional education and switch it to a kind of "remote emergency mode". In this scenario, educational institutions either canceled their activities or adopted a learning modality entitled Emergency Remote Education (ERE), with educators being released from their institutions and academic activities to work remotely, and students having remote classes at home (Joye, Moreira, \& Rocha, 2020). Mostly, all actions were taken with no planning or prior guidance on how to adapt classes and the teaching-learning process.

It is worth mentioning that the teaching currently practiced is a huge challenge, as it is not a distance learning model, in which there is regulation, but an emergency modality (Joye et al., 2020). In addition, everything points out that the ERE will last for a while in Brazil. The return to in-class traditional classes for all educators and students should not occur in such a close reality. Arruda (2020), for instance, pointed out that even with a strict lockdown in the most affected regions in China, schools did not return in less than five months. And yet, with strict sanitary procedures, this period should be even longer in Brazil for many institutions, since the country has become an epicenter of the disease. Therefore, it is essential to analyze how remote education has been practiced, showing the strategies adopted, but also the impacts caused.

Another point of interest related to ERE in Brazil is that Computer Science Education (CSE) takes place mainly in higher education institutions, such as universities. However, different approaches have been adopted by such institutions. Some decided to migrate classes to remote education, following the original schedule, while other institutions canceled/suspended their calendar. Thus, there is a rupture between the different strategies. As a consequence, Computer Science (CS) professors face two different scenarios: (i) they have had to quickly adapt their teaching materials for emergency remote classes; and (ii) they have suspended classes and are still (or were) considering how to switch to the remote model. As a result, the impact of this fragmented context is not yet evident.

Considering the aforementioned scenario, our main goal was to answer the following research question: How has ERE been conducted by CS professors in Brazil? We gathered responses from 137 participants from 69 educational institutions in 20 distinct Brazilian states. To the best of our knowledge, our study represents one of the most extensive ones analyzing the ERE scenario in Brazil. As main results obtained, we identified the strategies that are being adopted and the noticed impacts by CS professors. 
The remainder of this paper is structured as follows: In Section 2, we provide an overview of the background information that supports the topics investigated in this work. In Section 3, we discuss the survey design and present an overview of the responses obtained. The results are presented in Section 4 and discussed in Section 5. We analyze the threats to validity in Section 6. Lastly, we draw conclusions and provide directions for future work in Section 7.

\section{Background}

This section presents an initial bibliographic survey of the main research found in the literature on which this work is based.

\subsection{ICTs and Pedagogical Practices in Education}

The educational area faces constant challenges and is considered essential for the democratization of teaching (Dias \& Albano, 2017). An educational change and the whole teaching-learning process depends on the teachers and their training, in addition to the pedagogical practices applied in the classroom (Novoa, 1992).

Pedagogical practices encompass both the planning and systematization of teachers' dynamics and processes that go beyond learning. The goal is to ensure the content and the activities are taught to the student in the best possible way, in addition to creating mechanisms for students to mobilize their previous knowledge within an educational space. The teacher must know how to collect the learning from other sources, from other worlds, from other logic, to incorporate them in the quality of his teaching process and in the expansion of what is considered necessary for the student's pedagogical moment (Franco, 2016).

In this context, Information and Communication Technologies (ICTs) can be used and integrated into pedagogical practices, enabling improvements in the teaching-learning process, since the growing use of digital technologies and interactive communication networks accompanies and amplifies a profound mutation in the relationship with knowledge, prolonging certain human cognitive capacities (Levy, 1999).

Espíndola, Struchiner, and Giannella (2010) discuss this integration of ICT in teaching, as a process of change and innovation in pedagogical practices. The study cites three models that can be used in the field of educational technology:

1. Innovation Diffusion: The Innovation Diffusion Model aims to characterize how innovation is disseminated through certain communication channels. In the educational context, it was possible to identify two main types of studies that investigate this process of integration with ICTs by teachers: (i) studies that analyze the individual experiences lived by teachers during the process of adopting and implementing ICTs; and (ii) studies that analyze teachers' perceptions and attitudes towards the potential and limitations of ICTs.

2. Concerns-based Adoption Model: This model aims to describe the processes of change in teaching and assumes that the incorporation of new practices in teaching is not a one-off event, it is a process in development and personal experience for each teacher. 
3. Apple Classroom of the future: This program started with the idea of equipping classrooms with computers, believing that the presence of technological tools alone would stimulate the transformation. Over time, it has changed to be centered on the transformation of pedagogical practices with the use of computers, with initiatives to train teachers.

The models aim to contribute to research on the integration of innovations in teaching, from a procedural approach that understands the teachers' experience with the use of ICTs as something dynamic and transitory, which varies according to the individuals and the contexts involved. The teacher is the main agent of change in education since they are researchers in educational practice and must contribute to the conceptual design of innovations based on their theoretical and experiential knowledge. In view of the current scenario and the Covid-19 pandemic, the integration of ICTs in education becomes even more necessary in the face of non-emergency remote education.

\subsection{Resources to Support Computer Science Education}

Despite the sudden shift from teaching to remote mode, teachers were able to rely on existing resources to support the transition to this format, as there are several educational resources available on the Internet, especially for CS distance learning. For instance, Tovar, Chan, and Reisman (2017) created a repository community composed of textbooks, courses, assignments, quizzes/tests, among others teaching materials for CS and Information Technology. Similarly, Combefis, Moffarts, and Jovanov (2019) proposed a digital library with resources to teach and learn CS topics. These aforementioned initiatives have characteristics in common, such as the availability of free and open teaching materials to be used, reused and shared among students and educators. To facilitate understanding, in this paper, we have adopted the term Open Educational Resources (OERs) to represent such materials. In short, OERs are also known as digital resources and educational objects commonly stored in digital repositories with permissive licenses.

In the Brazilian context, there are similar initiatives on remote learning, sponsored mainly by public policies. However, such initiatives were not designed to support emergency education and they focus on distance learning and the adoption/availability of educational resources, such as OERs. Sistema Universidade Aberta do Brasil (UAB) ${ }^{1}$ can be pointed out as an example, since UAB aims at: (i) the offering of courses for teachers; (ii) the provision of higher education courses for educators; and (iii) the establishment of a national system of distance higher education. According to Ferreira and Carneiro (2015), the Brazilian educational system was composed of 104 higher education institutions in 2014. Such institutions offered 1,103 courses, reaching a total of 96,593 graduates.

The emergence of UAB spurred other initiatives and strategies for storing and disseminating the knowledge produced. In this sense, we highlight Repositório Aberto ${ }^{2}$, which is a UAB institutional repository aiming to digitally bring together a set of scientific publications from the University. Another initiative is EduCapes repository ${ }^{3}$, which includes open teaching materials that can be used by students and educators at different levels of education. The repository has

\footnotetext{
${ }^{1}$ https://www.capes.gov.br/uab

${ }^{2}$ https://repositorioaberto.uab.pt/

${ }^{3}$ https://educapes.capes.gov.br/
} 
a wide range of resources, which vary in different types, such as images, videos, animations, digital classes, and so on. In the collections of such repositories - and many others -, there are several types of materials capable of assisting ERE. Research, scientific publications and teaching materials are offered freely and can be reused in different contexts. Despite the existence of open artifacts, which can also support emergency remote education, there are questions about whether this structure is capable of withstanding the moment of crisis and whether they are being used, particularly in CSE.

\subsection{Related Work}

Although ERE is a new reality for most students and educators, researchers are already investigating the topic. For instance, Arruda (2020) presented an overview on the impacts observed in education during the quarantine period imposed by Covid-19. The author introduced a specific agenda to direct educational policies at a time of crisis, considering the Brazilian scenario. However, the approach adopted had some limitations: (i) the data were collected in previous years and, therefore, may not be updated; and (ii) the approach was based on a general view, susceptible to generalization risks.

Joye, Moreira, and Rocha (2020) investigated the intersection of distance education and ERE through actions taken by higher and basic educational institutions in Ceará, Brazil. However, as the authors carried out a regional analysis, the results observed may not be generalized for the whole country, in addition to being difficult to replicate. Another point to consider is that the study did not analyze private education. Similarly, Castaman and Rodrigues (2020) analyzed the topic from another perspective: the discussion is focused on the students' perceptions, and in the context of the Brazilian Federal Institutes of Education. Thus, universities and public schools were disregarded, as well as the entire private educational system.

In the international research context, Karalis (2020) presented a proposal for responding to emergencies in education, motivated by the Covid-19 pandemic crisis in educational systems. As a main limitation, the proposal needs adaptations to be used in diverse contexts due to the variability of the teaching and learning process around the world. Furthermore, due to the urgency scenario, it is difficult to measure whether the results achieved with the proposal are actually tangible.

Finally, another contribution is the study conducted by Zhang, Wang, Yang, and Wang (2020), which analyzed how the Chinese educational system has been dealing with the crisis caused by the quarantine. Although the discussions are relevant to ERE strategies, the particularities of the Chinese educational system prevent generalizations for most countries on the globe.

\section{Survey design}

Considering the scenario previously discussed, we aimed to investigate how CSE has been carried out in an emergency way. We surveyed CS professors, of public and private educational institutions in Brazil, to gather the noticed impacts and also the adopted strategies. In our survey, we followed the guidelines proposed by Linåker, Sulaman, Maiani de Mello, and Höst (2015). 


\subsection{Research Objectives}

The first step was to define the research objectives to establish the scope of our investigation. In this sense, our main objective was to answer the following research question: How has ERE been conducted by CS professors in Brazil? More specifically, we are interested in identifying the impacts perceived as well as the strategies adopted in the current educational emergency scenario.

\subsection{Target Audience}

To define the target audience of the survey, we adapted the guidelines of de Mello and Travassos (2016) to select potential participants. Table 3.2 shows the main concepts and descriptions.

\begin{tabular}{ll}
\hline Concept & Description \\
\hline Target Audience & Brazilian Professors \\
\hline Subject & ERE \\
\hline Unit of analysis & CS professors \\
\hline & We used three main sources: \\
Source of Population & - i) E-mail lists \\
& - ii) Social networks groups \\
& - iii) Institutional e-mails
\end{tabular}

We adopted following plan:

Population Search Plan

- To reach (i), we selected mailing lists from Sociedade Brasileira de Computação

- To reach (ii), we sent invitation to groups of CS professors

- To reach (iii), we sent e-mails for institutional e-mail of CS professors

\begin{tabular}{ll}
\hline Sampling Frame & Technical and higher education professors from public or private institutions \\
\hline Sampling Strategy & $\begin{array}{l}\text { Non-probabilistic (Convenience sampling) sample was divided between professors } \\
\text { who are teaching in ERE and those who are planning their classes }\end{array}$ \\
\hline Recruitment Strategy & $\begin{array}{l}\text { We prepared a standard message that was sent to the three population sources. The } \\
\text { message contained the invitation, survey link, deadline and general information }\end{array}$ \\
\hline Characterization Questions & $\begin{array}{l}\text { We used answer options depending on the nature of each question. In general, the } \\
\text { questions were answered with free text to be filled out or with a list of options. }\end{array}$ \\
\hline
\end{tabular}

In short, our focus was to gather responses from CS professors who work in Brazilian educational institutions. The aim was to map the impacts and strategies that such professionals are using through the quarantine period imposed by the Covid-19. CSE is offered in Brazil in three modalities: technical education, undergraduate programs, and graduate programs.

\subsection{Instrumentation}

To collect data, a web-based questionnaire ${ }^{4}$ was designed with questions that map to the defined research question. The questionnaire was available to participants from 10 June 2020 to 10 July 2020. The questionnaire was composed of two parts: Consent term, consisted of the consent term.

\footnotetext{
${ }^{4}$ https://drive.google.com/drive/folders/1qGkbN2-3agjhRuBMFP6KtXN7q7sGLAmN
} 
The participants should read and agree to access the questionnaire; and General questions, a set of questions to collect participants answers about the ERE of CS.

The questionnaire contained questions of various types, depending on the type of data to be extracted: multiple choice, checkboxes, dropdown, and open questions. When appropriate, the questions presented open options for the participant complement their answer.

\subsection{Evaluation}

After designing the questionnaire, we conducted a pilot test with participants. The focus of the pilot test was to verify the clarity and understanding of the questionnaire, collecting points of improvement and corrections. In addition, we intended to check the reliability and validity of the research instrument. For this purpose, three participants were invited to participate because they are CS professors and/or have solid experience in conducting surveys.

As the main result of the pilot test, we identified and rewrote questions with ambiguous interpretation. The participants also suggested changes to show clearer instructions in questions, such as using descriptions and examples. To address this potential issue, we included descriptions and objective examples in the necessary questions. After making adjustments, we sent the invitation to participate in the study to the potential respondents.

\subsection{Data extraction and synthesis}

To perform the data extraction, we tabulated all the answers obtained in an electronic spreadsheet. Then we removed the entries considered invalid (participants who had not completed the survey or had sent duplicate data), reducing the insertion of bias.

To carry out the data synthesis, we performed three distinct steps: Firstly, we analyzed the answers of each question and classified it as valid or invalid. An invalid answer, for example, is an answer that does not address the scope of the analyzed topic, often with inconsistent or contradictory arguments. Besides, some participants were teaching classes at the ERE period while others have their schedules suspended. Therefore, each response was analyzed individually according to the observed context and marked as valid or invalid. In addition, the questionnaire had free options and also a final field for comments. So, if any participant stated that their work context was not relevant, their response was also considered invalid. Also, in this step we also removed responses with ambiguous interpretations from the analysis. Secondly, we grouped valid responses by similarity, creating different categories. This was developed because there were responses with free fields and many participants sent extremely useful comments for the survey. Lastly, we quantified the total items for each category. It should be noted that the questionnaire was designed in Portuguese, and for the analysis we have translated the responses into English.

\subsection{Reliability and Validity}

Before presenting the results obtained, we verified the reliability and validity. The reliability is a property where different questionnaire applications provide similar results for the same participant (Wainer, 2007). In order to verify the survey reliability we used the internal consistency mechanism, as described by Kitchenham and Pfleeger (2002). Thus, we checked the responses of 
different questions about the same concept, checking if they would achieve similar results. For this we checked the total tools presented by each participant in a question $\left(P_{t}\right)$ and compared with the responses of the way that ERE was practiced by him $\left(P_{u}\right)$. In order to prove the reliability the tools $\left(P_{t}\right)$ should support most of the items described in their practice $\left(P_{u}\right)$. We used the Cronbach's alpha to check this and defined a confidence interval of $0.7(\alpha>0.7)$. In short, the value obtained should be greater than 7 to prove the survey reliability. As a final result, we obtained $\alpha=0.8499$.

According to Wainer (2007), validity means that what is measured by the instrument is a good approximation of the latent variable to be measured. In this context, our survey validity is related to the designed questionnaire being able to identify how ERE has been conducted by CS professors in Brazil. To check this, we used the content validity. In summary, an expert researcher was responsible for reviewing the questions elaborated to verify if it was possible to measure the observed phenomenon.

\subsection{Respondents Profile}

We received 137 responses from CS professors in total. Participants were firstly asked about general information, such as the state in which they live, the educational institution in which they work, teaching modality adopted by the institution, and so on. We gathered information about the institution in which the respondents teach. In short, 78.10\% (107 answers) of respondents teach in the public education sector, whereas $21.90 \%$ (30 answers) are from the private education sector. Concerning the number of participants per state in Brazil, we had a higher number of participants in the Southeast and South regions of the country, as can be seen in Figure 1.

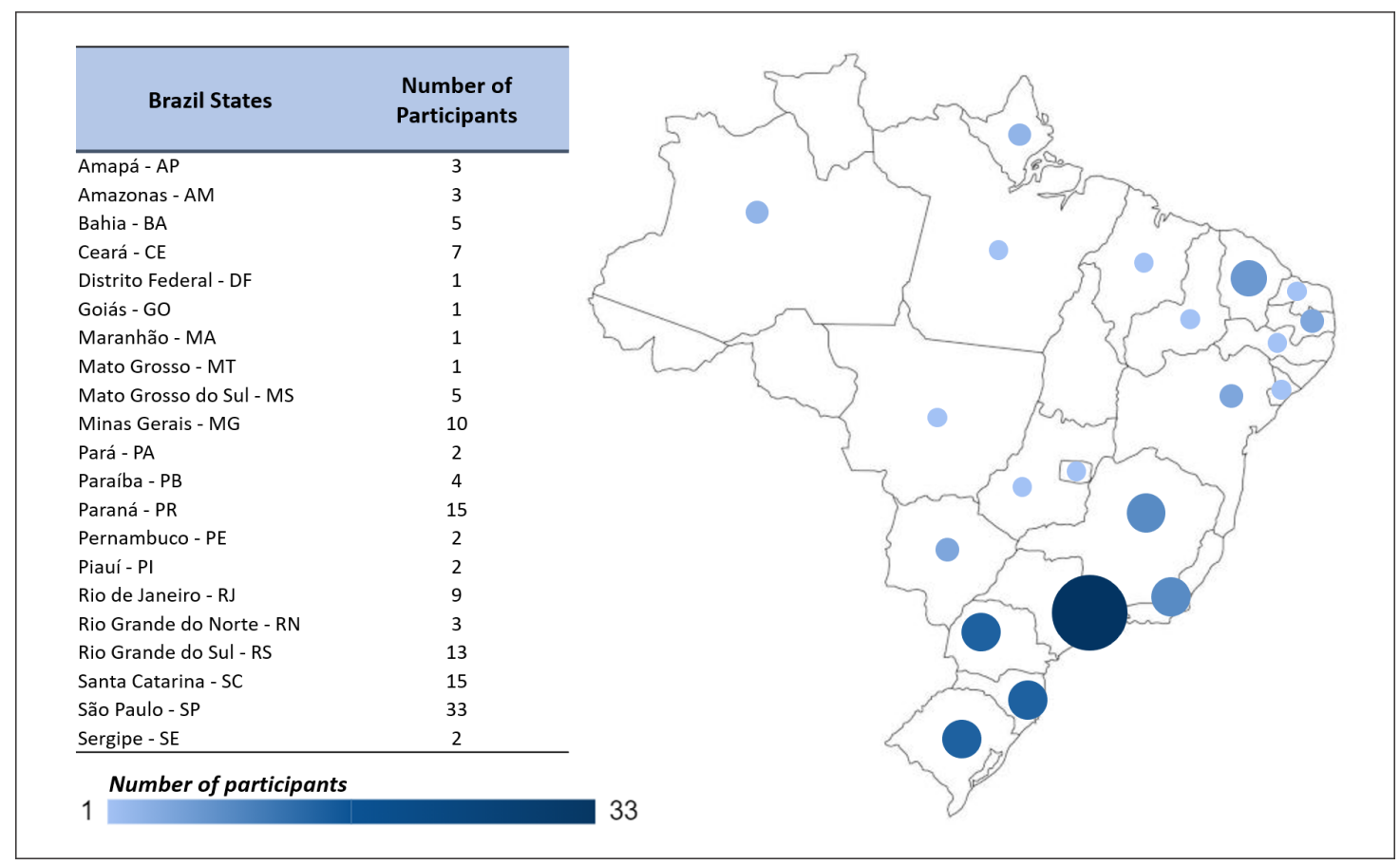

Figura 1: Number of participants by states in Brazil. Source: Research data.

Regarding the teaching modality most used by the survey respondents' institution was, we can highlight in-class - traditional (133 answers). Only five institutions adopt blended learning 
modality and three distance learning, as can be seen in the Figure 2. We identified that the respondents teach at 69 different Brazilian institutions, which offer different levels of programs: Technical, Undergraduate, Graduate (lato sensu), and Graduate (stricto sensu) ${ }^{5}$.

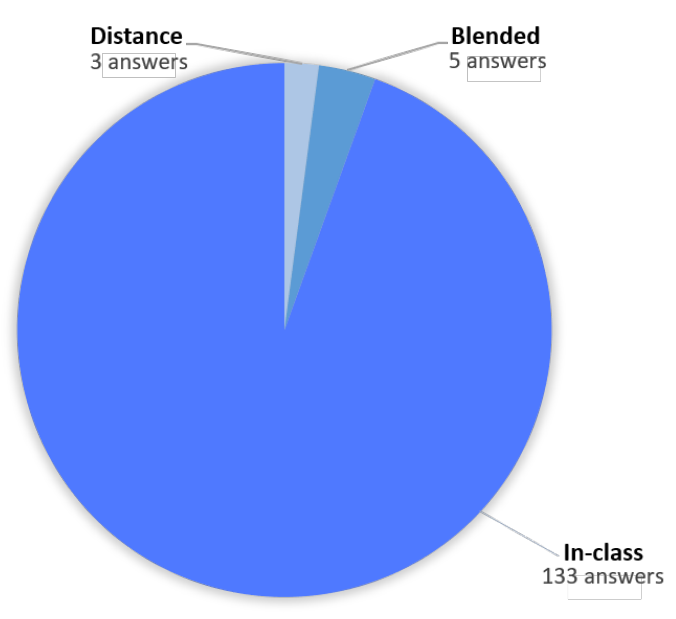

Figura 2: Teaching modality used by institutions. Source: Research data.

Tabela 1: Participant's degree programs.

\begin{tabular}{llc}
\hline Degree level & Degree Program Name & Number of participants \\
\hline \multirow{2}{*}{ Technical } & Informatics & 21 \\
& Analysis and Systems Development & 9 \\
\hline & Analysis and Systems Development & 5 \\
& Computer Science & 78 \\
& Computer Engineering & 38 \\
& Computing & 3 \\
Undergraduate & Electrical Engineering & 3 \\
& Information Technology & 2 \\
& Information Systems & 49 \\
& Science and Technology & 2 \\
& Software Engineering & 13 \\
& Systems for Internet & 1 \\
& Other & 2 \\
\hline Graduate (lato sensu) & Computing areas & 13 \\
\hline Graduate (stricto sensu) & Master's and/or Doctorate & 54 \\
\hline
\end{tabular}

Note: The total number of participants is greater than the number of respondents as they can work in more than one degree program.

As can be seen in Table 1, Computer Science, Information Systems, and Computer Engineering degree programs were mentioned by the majority of the respondents as the degree program in which they teach. Several courses are taught by such participants, with emphasis on courses involving the programming area and software engineering ${ }^{6}$.

\footnotetext{
${ }^{5}$ https://bit.ly/respondents-institutions

${ }^{6}$ https://bit.ly/course-institution
} 


\section{Results}

\subsection{Impacts}

To identify the impact noticed by the professors, we initially asked if they had to adapt the teaching materials during the emergency period. As can be seen in Figure 3, teaching materials adaptations were made by most participants. Of the total $(n=137)$, only 8 professors did not need to change the teaching material, while 129 did need. As shown in Table 2, we noticed professors from both public and private institutions were impacted by this problem, with the majority having to adapt their materials.

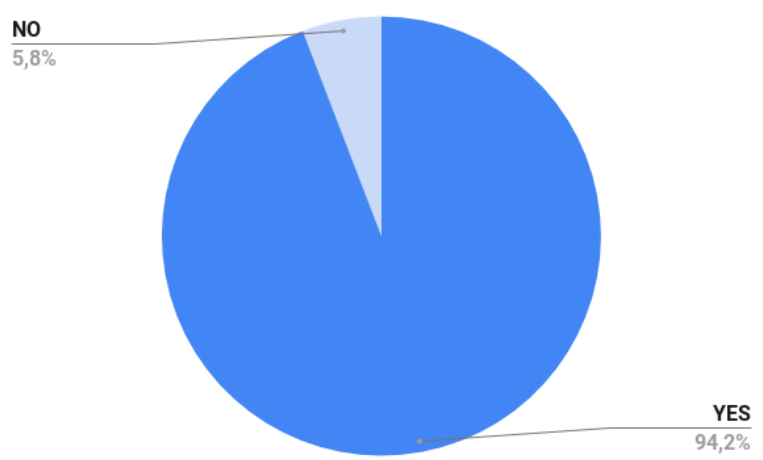

Figura 3: The overview on adaptation of teaching materials during the ERE. Source: Research data.

Tabela 2: The adaptation of materials by sector.

\begin{tabular}{|c|c|c|c|}
\hline Institution & $\begin{array}{l}\text { Was it necessary to adapt your teaching materials to the Emergency } \\
\text { Remote Teaching modality? }\end{array}$ & Total & $\%$ \\
\hline \multirow{2}{*}{ Public } & Yes & 100 & $72.99 \%$ \\
\hline & No & 7 & $5,11 \%$ \\
\hline \multirow{2}{*}{ Private } & Yes & 29 & $21.17 \%$ \\
\hline & No & 1 & $0.73 \%$ \\
\hline
\end{tabular}

We also asked the participants which were the main impacts noticed during the ERE, considering a list of several impacts and also the possibility of citing new ones. In this context, 4 participants revealed that the ERE had not yet impacted their routine (e.g., classes had just started, suspended schedule, etc). Therefore, these answers were considered invalid for this analysis. As a result, answers from the remainder participants $(n=133)$ were considered and we obtained a total of 544 items to be analyzed. Next, the items were grouped according to their similarity, totaling six major categories. The most cited one was the impact on interaction with students (such as hold meetings and general interactions with students); followed by the assessment problems (how to assess students' performance?); then the impact on activities (such as exercises, projects, and homework) was pointed out; next, impacts caused by the need to record classes were raised; the problems in the adaptation of teaching materials were were fifth. Finally, pedagogical adaptations also remainder. The others items were classified as "Other", as shown in Figure 4. 


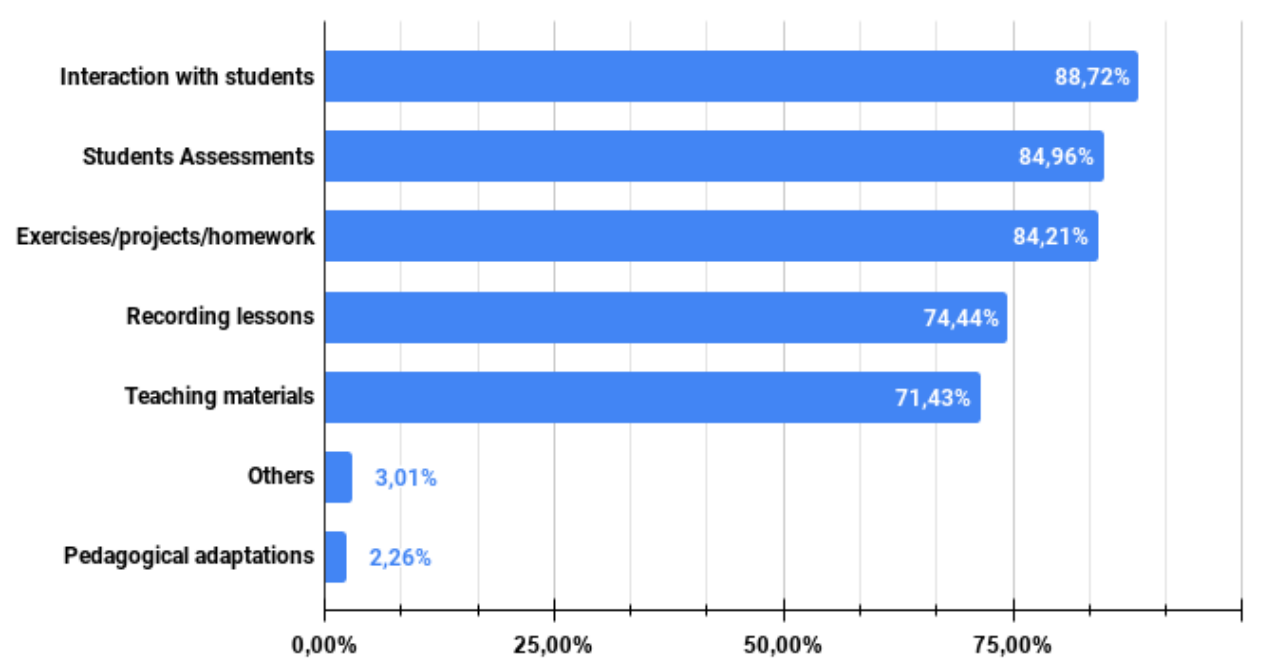

Figura 4: The impacts noticed by CS professors during the ERE $(n=133)$. The participant could cite 1 or more items. Source: Research data.

Next, we asked the professors about their previous experience with the development of materials for remote education. 69 participants $(50.36 \%)$ declared they had never had such experience. The remainder, 68 participants $(49.63 \%)$, stated they already had previous experiences with remote classes. In this context, 57 professors declared having developed teaching materials, such as slides or supporting texts, for remote teaching. Also, 49 professors stated having developed activities, such as exercises, projects, and homework to be used remotely. 38 professors declared having experience with video classes and 36 of them with conducting assessments remotely. Only 2 professors claimed to have developed e-books. Finally, the remaining answers were grouped as "Others". The complete data synthesis regarding the professors' experience with the development of materials for remote education is shown in Figure 5.

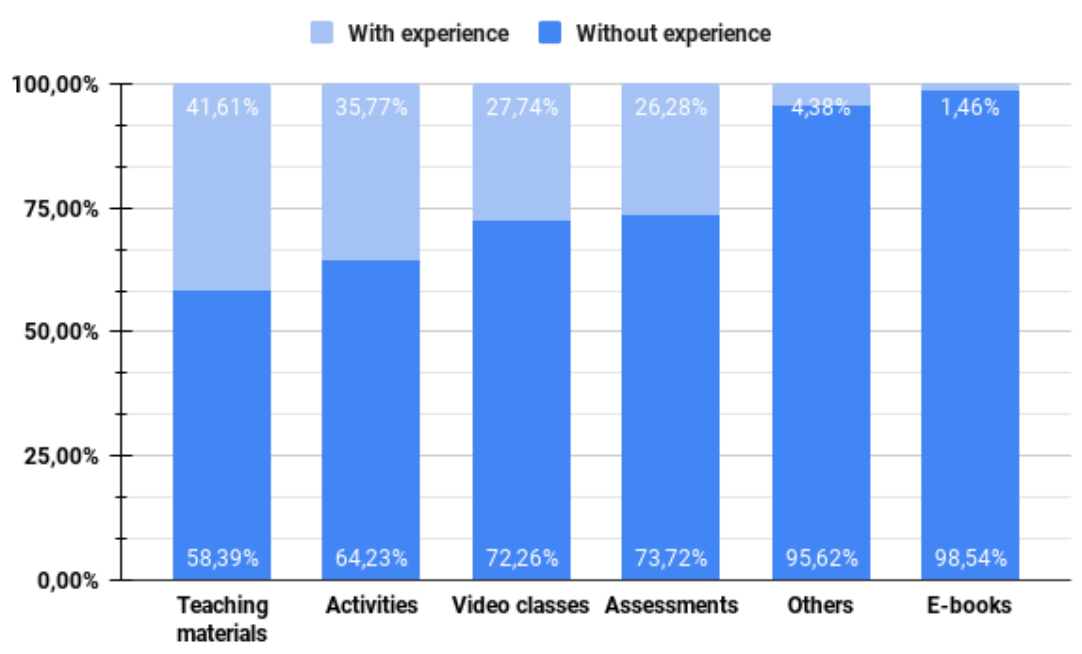

Figura 5: The experience (and the lack of it) with the development of materials for remote teaching $(\mathrm{n}=136)$. The participant could cite 1 or more items. Source: Research data. 
Participants were also asked about the major difficulties faced during the development of teaching materials for ERE. 7 responses were considered invalid (the respondent contradicted himself or reported not having enough experience yet) and, therefore, we considered a set of 130 responses. As it was a multiple-choice question, each professor could point several difficulties. In total, 393 items were considered. After grouping the data, we identified problems regarding: (i) creating and adapting assessments, activities, and teaching materials; (ii) difficulties regarding the lack of skills, such as editing/recording videos; and (iii) previous practice of remote teaching. Finally, broader challenges were identified, such as the lack of student engagement and the configuration of tools. Only 18 professors reported having no difficulties. Table 3 shows a scheme categorizing the main problems encountered. Yet in this perspective, we have not identified significant differences between public and private institutions. 3 professors from private institutions (2.30\% of total) and 15 professors from public institutions (11.53\%) stated having no difficulties.

Tabela 3: The main problems faced by CS professors during the ERE.

\begin{tabular}{llll}
\hline $\begin{array}{l}\text { When developing materials for Emergency Remote Education, } \\
\text { which of these difficulties did you notice? }\end{array}$ & Category & Total & \% \\
\hline \multirow{2}{*}{ When I must create or adapt } & Assessments & 79 & $60.76 \%$ \\
\cline { 2 - 4 } & Activities & 58 & $44.61 \%$ \\
\cline { 2 - 4 } & Teaching materials & 54 & $41.53 \%$ \\
\hline \multirow{2}{*}{ When I need use a skill to } & Video edition & 63 & $48.46 \%$ \\
\cline { 2 - 4 } & Video record & 62 & $47.69 \%$ \\
\hline \multirow{2}{*}{ I have others problems } & Teach remotely & 49 & $37.69 \%$ \\
\hline I haven't difficulties & Tool configuration & 2 & $1.53 \%$ \\
\cline { 2 - 4 } & Engagement & 2 & $1.53 \%$ \\
\hline
\end{tabular}

We noticed the use of different types of digital tools, such as software for web conferences and social networks, to support ERE. Many of these, however, were not adopted in the traditional model, being opposed by many professors, such as the use of WhatsApp and Instagram. Considering the responses obtained, we identified that most participants use, in average, three different tools. But these results may vary, there are cases of professors who reported using up to seven tools, as shown in Figure 6.

Such tools have been used in different ways, varying according to the professor's needs and the obligation on the part of the educational institution. Tools commonly used by Brazilian institutions, such as Moodle, remained being used. Other tools, however, were adopted due to the current context. In Table 4, we present a summary of the main categories of tools used and Figure 7 shows the most used tools. As shown, WhatsApp, Youtube and Google Classroom are tools used by most CS educators. 


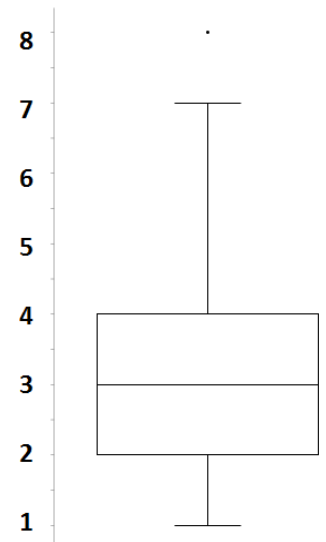

Figura 6: The number of tools used by CS professors in ERE $(n=134)$. The participant could cite 1 or more items. Source: Research data.

Tabela 4: List of categories, descriptions, and tools used by CS professors.

\begin{tabular}{|c|c|c|}
\hline Main category & Category description & Tools identified \\
\hline Web conference & $\begin{array}{lcr}\text { Tools } & \text { for } & \text { creating } \\
\text { and managing } & \text { online } \\
\text { conferences } & \end{array}$ & $\begin{array}{l}\text { Cisco WebEx, Conferênciasweb, Google Meet/Hangout, } \\
\text { Jitsi, Mconf, Meet attendance, Meet.jit, Microsoft Teams, } \\
\text { RNP conferência, Webconf, Zoom Meeting, BBB }\end{array}$ \\
\hline $\begin{array}{l}\text { Educational } \\
\text { platforms }\end{array}$ & $\begin{array}{l}\text { Provide environments to } \\
\text { assist of classes }\end{array}$ & $\begin{array}{l}\text { Ambiente de Aprendizagem Virtual (AVA), Blackboard, } \\
\text { Google Classroom, SIGAA, Moodle }\end{array}$ \\
\hline Social network & $\begin{array}{l}\text { Use of social networks to } \\
\text { content, communication and } \\
\text { interaction }\end{array}$ & Facebook, Instagram, Skype, Whatsapp \\
\hline Video platform & $\begin{array}{l}\text { Video platforms, generally } \\
\text { provide video lessons }\end{array}$ & e-Aulas, Institution's Video Repository, Youtube \\
\hline $\begin{array}{l}\text { Communication } \\
\text { platform }\end{array}$ & $\begin{array}{l}\text { Provide communication } \\
\text { between professors-students }\end{array}$ & Email, Discord, E-disciplinas Chat, Slack, Telegram \\
\hline Class recording & $\begin{array}{l}\text { Use aimed at recording the } \\
\text { user's screen }\end{array}$ & ActivePresenter, Edpuzzle, Loom, OBS Studio \\
\hline Game platform & $\begin{array}{l}\text { Gamified educational } \\
\text { platforms }\end{array}$ & Kahoot \\
\hline Repository & $\begin{array}{l}\text { Use of digital repositories to } \\
\text { version files }\end{array}$ & $\begin{array}{l}\text { GitHub, GitLab, File repository, Private repository, Tidia, } \\
\text { Google Drive }\end{array}$ \\
\hline Exercise platform & $\begin{array}{l}\text { Adopted for exercise } \\
\text { correction and validation }\end{array}$ & Run.codes, Google Forms \\
\hline Interactive board & $\begin{array}{l}\text { Simulation of an interactive } \\
\text { blackboard for classes }\end{array}$ & Whiteboard \\
\hline Engagement & $\begin{array}{l}\text { Mainly used for students to } \\
\text { interact with the professor }\end{array}$ & Mentimeter \\
\hline Other & $\begin{array}{l}\text { Tools that do not fit into any } \\
\text { of the previous categories }\end{array}$ & $\begin{array}{l}\text { Institution tool, Meat, Metro Retro, One note, Padlet, } \\
\text { Paint, VS Live Share, Yammer, Movavi, Mediawiki, } \\
\text { Google Sites, Google tools, Google DOCs }\end{array}$ \\
\hline
\end{tabular}

\subsubsection{Revisiting the literature on impacts}

Recent studies have shown several Brazilian educators employ traditional teaching methods in different CS fields (e.g., Paschoal and de Souza (2018) and Marcolino and Barbosa (2017)). Therefore, CS educators usually apply evaluative activities and/or assessments to teach. Although 


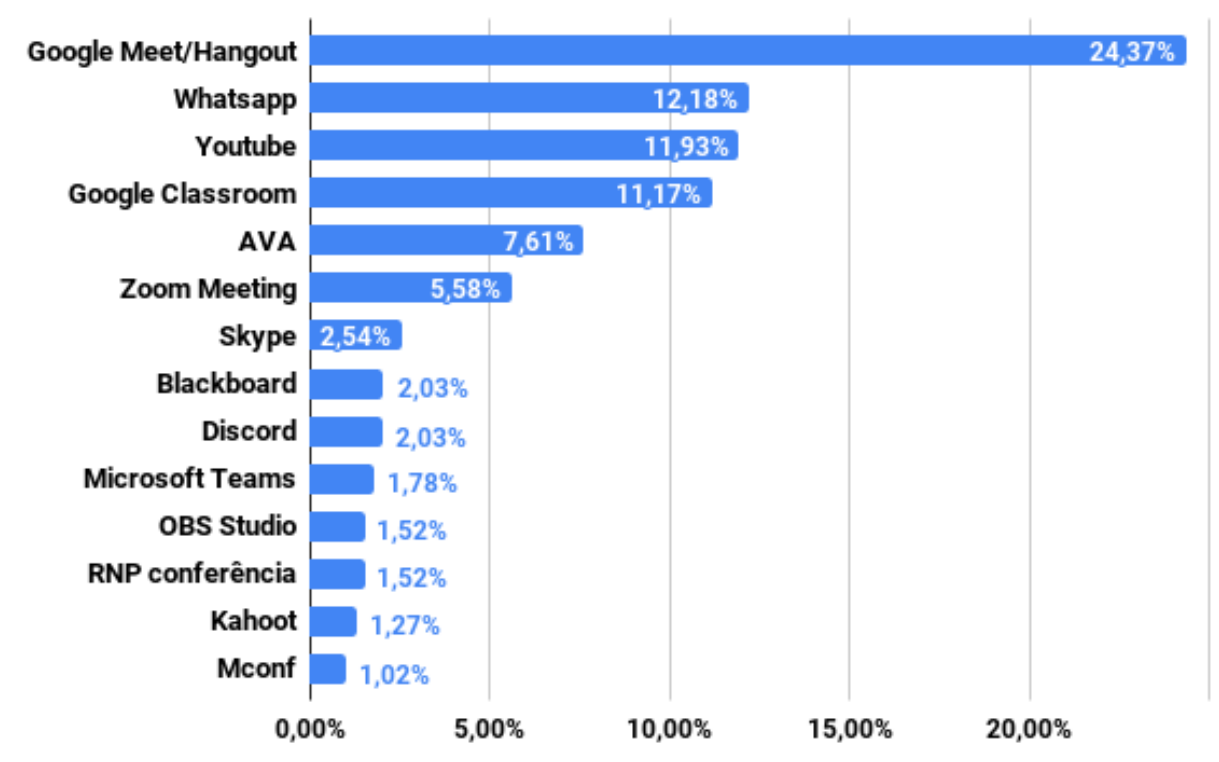

Figura 7: The tools most used $(\mathrm{n}=134)$. The participant could cite 1 or more items. Source: Research data.

there are some attempts to combine different teaching strategies, such an approach requires different strategies from in-classroom teaching, being a challenge in ERE. In this sense, in our survey, we identified that one of the main current difficulties of CS educators is related to create or adapt assessments, activities or teaching materials (see Table 3). In this perspective, the participants also commented students assessments and impact on exercises, projects, and homework as potential impacts (see Figure 4). On the one hand, as previously discussed, pedagogical strategies start with planning and systematizing the dynamics of educators. This process is systematic and involves a lot of observation and action by the professor. On the other hand, ERE changed this dynamic. The development and adaptation of the teaching materials (without time and experience with distance learning) can include several problems.

At the same time, the inclusion of ICTs can provide benefits to students and professors. As presented, the interaction with students was pointed out as the major impact to educators. Also, difficulties when the professor need create/adapt assessments and activities were mentioned. Among the tools described by participants, we identified several ICTs for exercise correction/validation, simulation of interactive blackboard for classes, and interaction with the professor. Also, many tools for web conferences and educational platforms are being used. In this context, Ferreira, Ambrósio, Nogueira, Ullmann, and Melo (2018) conducted a survey with CS students, in which they highlighted the importance of engaging students in solving real problems and clarifying their needs/expectations. Thus, the class dynamics (as questions and answers, solution of doubts) can be affected. In this perspective, ICT can include potentials solutions to support engagement among students and professors.

Finally, Brazil have an anomalous educational system with prestigious institutions (primary and secondary levels) in the private sector and with the situation reversed at higher educational level (McCowan, 2007). As commented by authors, most of the best universities in the country are public, funded and controlled by the federal government or the individual state governments. 


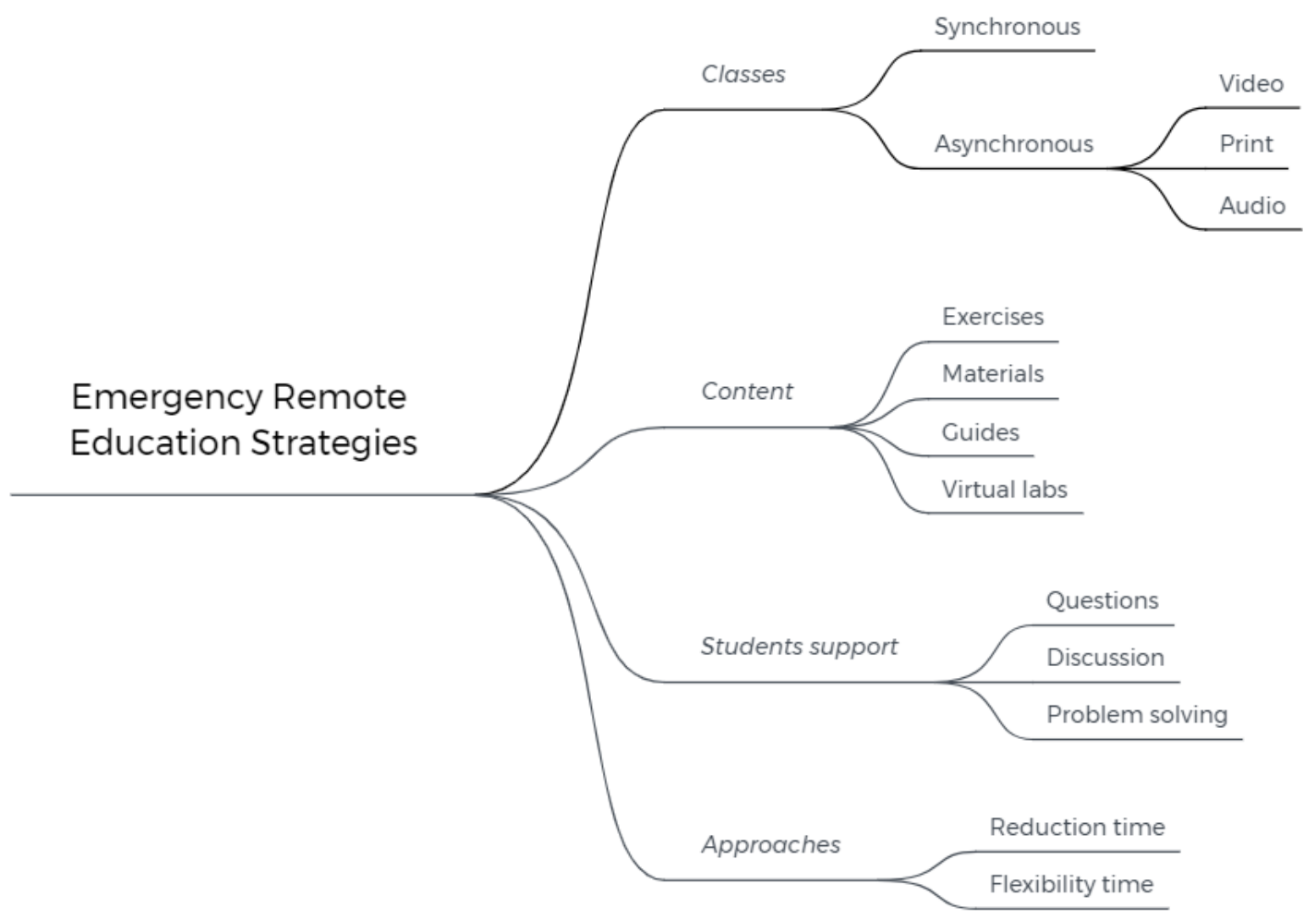

Figura 8: Summary of strategies used by CS professors during the emergency period in Brazil. Source: Research data.

are provided to students as a complement to the content. The guides are scripts developed by professors for the development of student practices. And virtual labs are content strategies that involve the use of digital tools for laboratory simulation.

The strategies used to provide students support were organized into three categories: questions, discussions, and problem solving. In the first case, to answer students' questions, professors commonly adopt individual web conferences with students for clarification. While discussions are held almost entirely in asynchronous forums, sometimes questions can be discussed in this way. Finally, problem solving is mainly done individually, since it is usually about a difficulty faced by that student, or how to set up a programming environment correctly. Generally, in these situations, the student shares his/her screen with the professor to show the error.

Finally, we also point out two different approaches adopted by professors for CS ERE: (i) reduction of class time, and (ii) flexibility in delivery/absence of deadlines. The reduction in class time is almost always a reflection of digital teaching. Thus, the classes (or video classes) are shorter than the traditional class schedule. Delivery flexibility makes reference to the dates that exercises/projects must be delivered. Similarly, this can be classified as the absence of deadlines.

As previously discussed, many professors reported challenges and problems during the development of ERE materials. Considering this scenario, we also investigated strategies currently being used to overcome such problems. Initially, we checked how professors are creating the teaching materials. When analyzing the responses, we collected 123 valid responses and noticed five items following the definitions of the 5Rs of openness (reuse, review, remix, redistribute and 
retain) provided by Wiley (2014). The remainder of the items were classified as "Personal" or "Others", as presented in Table 5.

Tabela 5: The summary of strategies identified.

\begin{tabular}{lllc}
\hline Category & Source & Description & \% \\
\hline Remix & (Wiley, 2014) & Create new teaching material based on other materials & $44.72 \%$ \\
Redistribute & (Wiley, 2014) & Share teaching materials with other teachers & $40.65 \%$ \\
Revise & (Wiley, 2014) & Update or modify teaching material already made available & $35.77 \%$ \\
Personal & Our survey & Create or adapt own materials & $16.26 \%$ \\
Others & Our survey & Responses that do not fit into any of the previous categories & $11.38 \%$ \\
Reuse & (Wiley, 2014) & Reuse teaching material & $31.71 \%$ \\
Retain & (Wiley, 2014) & Maintain copies of content such as files or references & $0.81 \%$ \\
\hline
\end{tabular}
Note: $n=123$. The participant could cite 1 or more items.

We also investigated the characteristics of materials used by professors. $67.88 \%$ (93 participants) reported the use of materials with permissive licenses, such as videos from YouTube and Coursera, projects hosted on GitHub, and scientific works. Due to the attributes, we labeled such materials as OERs, and aiming to provide an analysis, the remainder of this section is organized according to the use of OERs as a teaching strategy in Section 4.2.1. The challenges and reasons for not applying OERs are discussed in Section 4.2.2.

\subsubsection{The use of OERs during the ERE period}

Initially, participants pointed out which sources were used to find the materials used in classes. Of the 93 participants who answered this question, 4 responses were classified as invalid. As a result, 89 professors sent comments with one or more options and 313 items were collected. The dispersion of data is shown in Figure 9.

In summary, the items were grouped in eight different categories, according to the following structure:

- Video/courses platforms: Platforms for video classes or online courses. Some examples in this category include YouTube, Coursera, and so on;

- Digital libraries: Libraries with extensive collections of digital items, such as ebooks, book chapters, preprint of studies, and so on;

- Image sources: Image repositories (like Flicker) or image search engines (like Google Images);

- Open source repositories: Repositories dedicated to hosting project source code, such as Git Hub, Source Forge, etc;

- Educational sites/blogs: Sites, blogs, projects or digital initiatives that provide educational materials. Some examples include teacher blogs, discussion forums, etc;

- Institutional repositories: Repositories created by the educational institution to disseminate the materials developed by students, professors, and researchers. Examples include repositories of theses, dissertations, etc; 
- Podcast platforms: Digital podcast platforms such as Spotify and Google podcast;

- OER repositories: repositories dedicated to the storage and dissemination of OER of all types. Merlot and OER Commons are some of the examples in this category;

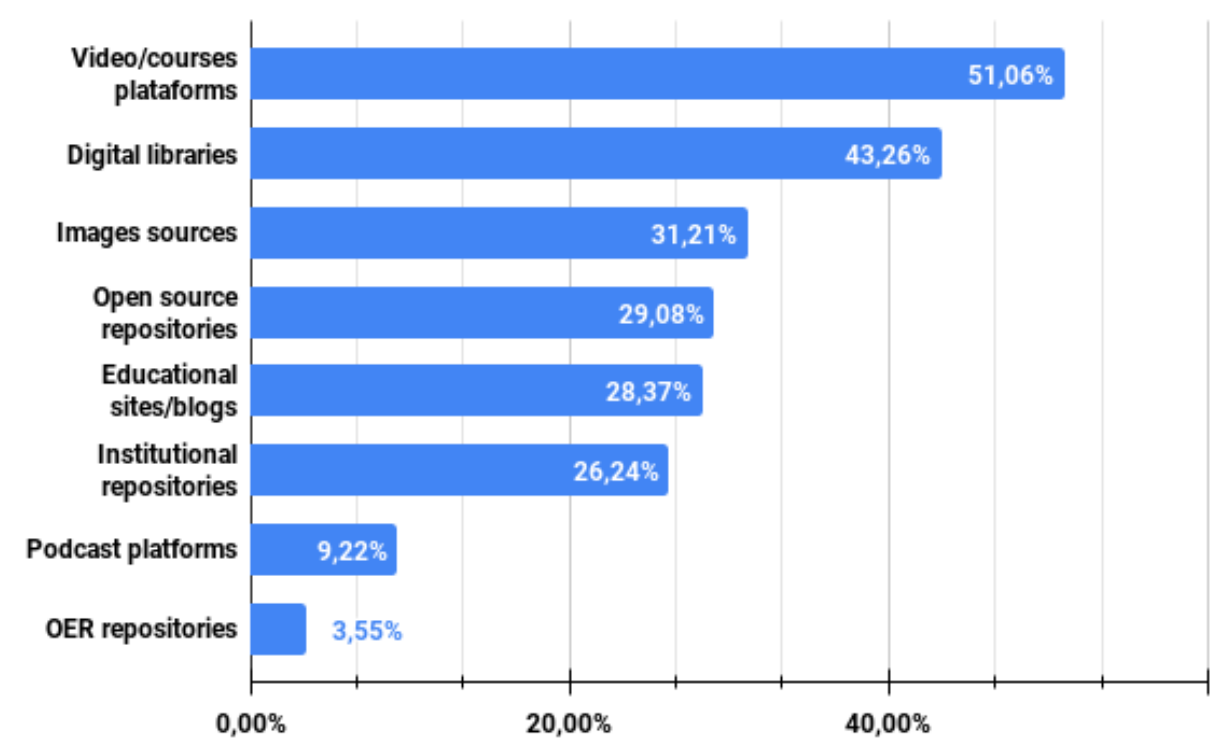

Figura 9: The OER sources used $(n=89)$. The participant could cite 1 or more items. Source: Research data.

We also asked what were the most common types of resources used by CS professors, since the same source can present different types of materials. 92 responses were considered valid. Similarly, eight categories were identified, as shown in Figure 10. The most cited by the participants was the use of videos, such as video lessons, videos from other professors, and videos about the theme studied. The teaching materials were also highly referenced, such as slides or supporting texts. We also noticed a great emphasis on the use of digital book and exercises, projects, or homework. Scientific studies, such as articles, have also obtained a high rate of use by professors. Finally, we also identified the recurrence of the use of images, podcasts, and posts, commonly made in digital media, such as personal blogs.

Next, we asked how these materials are being used by professors. The responses could include one or more options, so we collected 192 items in total. Most of the participants stated that they use OERs as a reference material. In short, OERs are offered as support for students to consult. Besides, participants also stated that they adopt OERs to create/adapt teaching materials or use them to prepare exercises, projects, and homework. Table 6 shows the responses categorized.

\subsubsection{The challenges of OERs}

We asked 44 participants, who have not used OERs for emergency education, the reasons for such decision. As a result, 42 professors presented responses considered valid. Then, these answers were grouped into ten different categories, presented in Figure 11. 


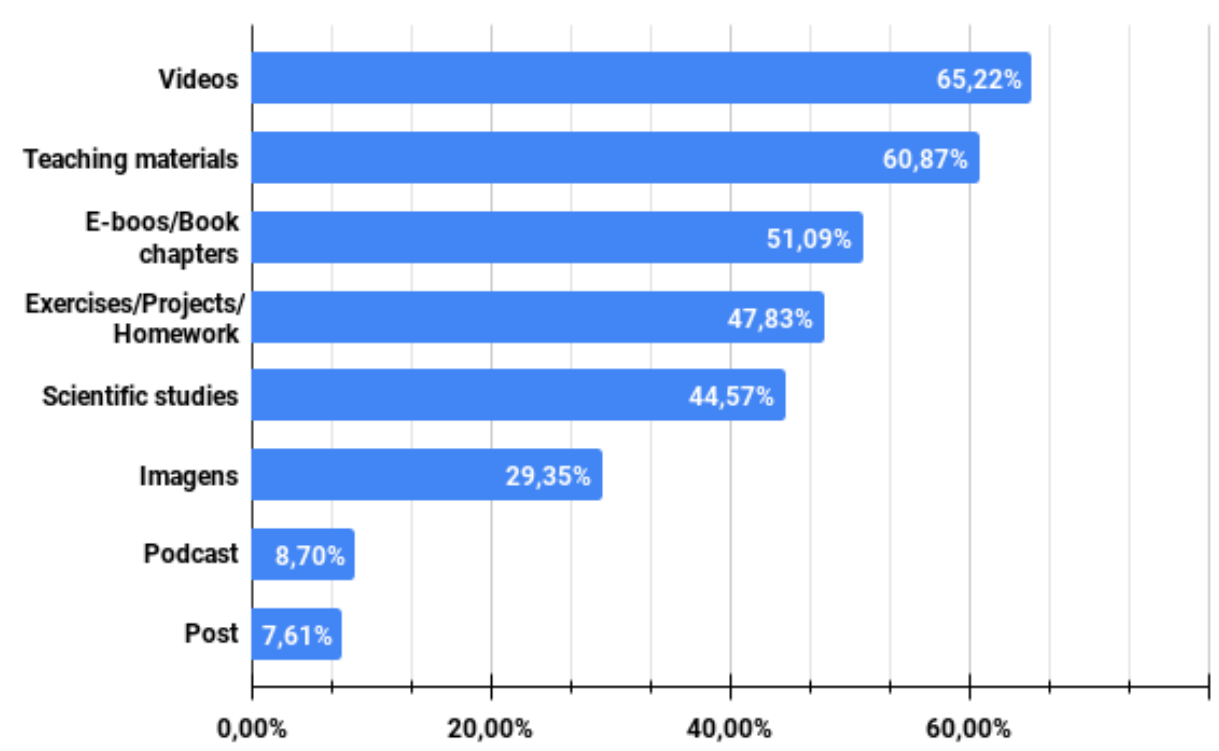

Figura 10: Resources types most used in ERE $(n=92)$. The participant could cite 1 or more items. Source: Research data.

Tabela 6: The use of OER in ERE.

\begin{tabular}{llc}
\hline Use & Examples & \% \\
\hline Complementary material & Supporting materials & $40.41 \%$ \\
Creation/adaptation of materials & Slides & $30.57 \%$ \\
Preparation of activities & Exercises, homework & $28.50 \%$ \\
\hline
\end{tabular}

Note: $\mathrm{N}=91$. The participant could cite 1 or more items.

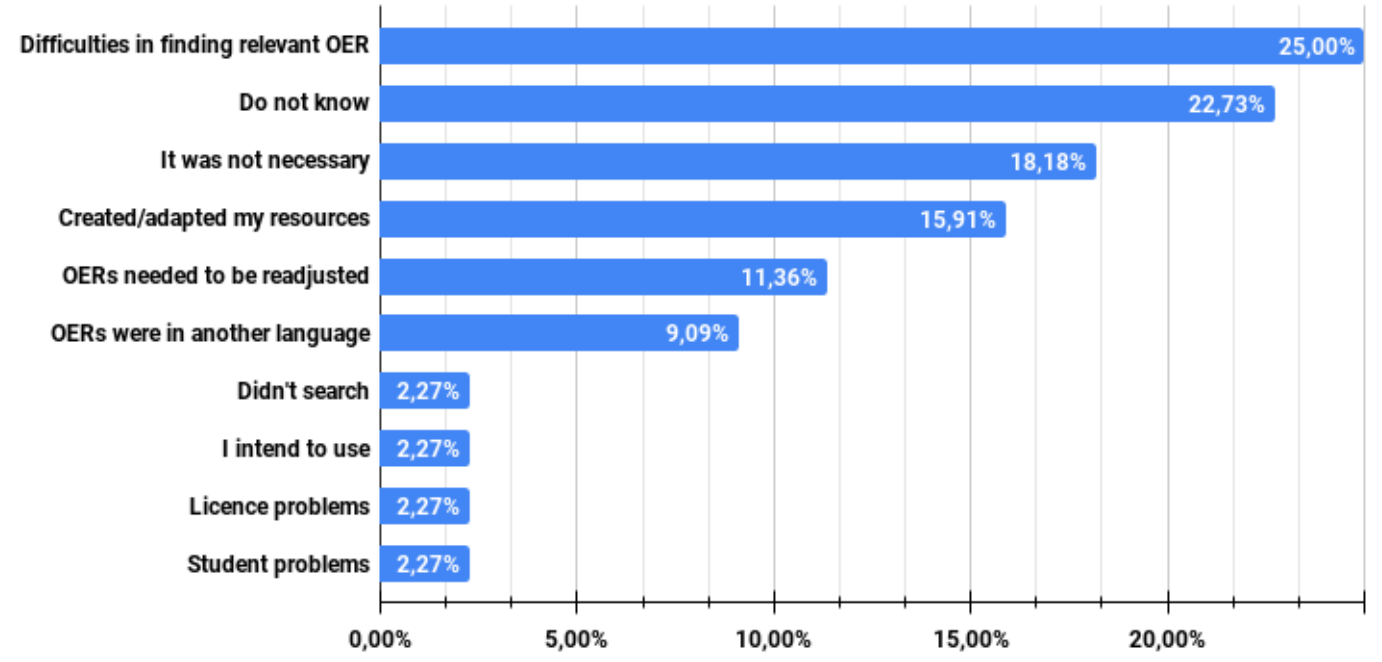

Figura 11: Summary of the problems faced by professors in the adoption of OER during the ERE $(n=42)$. The participant could cite 1 or more items. Source: Research data.

Commonly, participants point out problems in finding relevant resources. Next, some participants reported not knowing OERs. Also, the arguments about there being no need and preferably creating own resources were frequently raised by the respondents. The challenge of 
readjusting a resource or the need to translate it was also pointed out by the participants as barriers in the use of OERs. Finally, personal aspects as I didn't search for OER; I didn't use it, but I intend to use it; I had problems with licenses; and, problems with students (which they may question the reason for using external materials) were also presented, but with less incidence.

Next, we asked the professors who did not use OERs whether such resources could be useful for teaching CS. To this, participants rated between 1 (strongly disagree) and 5 (strongly agree) the following statement: "Do you believe that OERs can be useful for teaching computer science?". As can be seen in Table 7, most of the participants agreed with the statement: $63.63 \%$ of the responses rated the level of agreement as 4 or $5 ; 29.54 \%$ selected option 3 ; and $6.82 \%$ of the participants classified the statement as 2 or 1 .

Tabela 7: Answers to the question: do you believe that OERs can be useful for teaching computer science?

\begin{tabular}{|c|c|c|c|}
\hline Classification & Participants & \% Participants & Argument example \\
\hline 1 & 2 & $4.55 \%$ & "I don't know [what are OER]" \\
\hline 2 & 1 & $2.27 \%$ & - \\
\hline 3 & 13 & $29.54 \%$ & $\begin{array}{l}\text { "I don't know how to give an opinion. I never used such } \\
\text { materials" }\end{array}$ \\
\hline 4 & 17 & $38.63 \%$ & $\begin{array}{l}\text { "If it is good material, didactic and appropriate to the } \\
\text { level of the class, it can help" }\end{array}$ \\
\hline 5 & 11 & $25.00 \%$ & $\begin{array}{l}\text { "I believe that a way to better publicize OER should } \\
\text { be created. The creation could be through a new } \\
\text { community or dissemination of an existing community for } \\
\text { this purpose. At the moment, I am not aware of pages, } \\
\text { social networks and the like for the dissemination of OER } \\
\text { for Computer Science" }\end{array}$ \\
\hline
\end{tabular}

Note: There was no argument for classification with 2 value.

As seen, most of the arguments considering the lowest classifications (1,2, and 3) about the use of OERs for CS pointed to the unfamiliarity of the CS professors. The higher classifications (4 and 5) pointed to interesting paths, such as the recognition of the benefits that such materials can provide and also the need of a more efficient dissemination of them.

\subsubsection{Revisiting the literature on strategies}

Researchers have argued that the academic curriculum must be developed with the use of technology. For instance, according to Oliveira, Schneider, and Kim (2020), by promoting technological literacy the students will become familiar with the latest technologies. Although the authors have already warned about little attention on this theme, ERE has added several barriers in the Brazilian context. In the responses collected, a problem between CS degree and the technological literacy was identified. In this sense, among the strategies used to design the classes, we highlight the use printed classes, and the content we identify the use of traditional materials (e.g., exercises, teaching materials, and guides). Obviously, promoting the technological literacy of students within this context is a difficult and probably impossible task. At same time, the use of these strategies may be linked to the great social inequality and historical problems of access to education in Brazil. Educators may be using strategies to democratize access (e.g., audio and printed classes), so students without internet (or limited access) may access the content. However, we identified these action only in public institutions. 
Also, pieces of evidence collected by our survey showed that many CS professors adopt the 5Rs of the openness, organized by Wiley (2014), as a strategy during the ERE. Although it is common to use practices among CS professors such as remixing and redistributing the teaching material, we identified several problems. On the one hand, the OERs, teaching and learning materials available on the internet with permissive licenses, are being collected from well-structured sources (such as video/courses platforms, digital libraries, images sources and open source repositories). These sources generally have extensive collections with resources from different areas of knowledge grouped together and they may often not have only OERs, such as YouTube. On the other hand, OER repositories can provide formidable support to students and educators when they need to use already available learning materials (Medio, Limongelli, Sciarrone, \& Temperini, 2020). In CSE context, due to the interest of students and educators, many initiatives are focused on creating repositories and spaces dedicated only to the CS area, as presented by Combefis, Moffarts, and Jovanov (2019) and Tovar, Chan, and Reisman (2017). Furthermore, commonly the OER repositories have in their collections all types of materials used by CS educators (shown in Figure 10). However, OER repositories was cited as the least used source by educators (see Figure 9). Probably, the reason for this behavior must be the educators' lack of knowledge and also the difficulty of finding a relevant resources in these collections, as commented in Table 7 and Figure 11. Besides, this finding dialogues with the literature, which cites the identification of relevant resource as one of the greatest challenges of OERs.

In a related perspective, Marcolino and Barbosa (2017) presented that many Brazilian educators were already using materials from courses provided by Udacity and Coursera to support programming education. In our survey, we also identified this occurrence, but in the context of CSE. As presented in Figure 9 and Figure 10, video/courses platforms are the most used by CS professors during the ERE. However, in ERE the CS educators are not only searching for technical materials from these courses (e.g., ideas or learning materials) as commented by Marcolino and Barbosa (2017), but the complete videos and courses to support their students. In this sense, ERE may have accelerated the use of these materials in the routine of CS professors and students.

In short, considering the observed results, we noticed that CS professors are teaching in the emergency model adopt multiple approaches. Different sources of resources have been mapped, as well as different types of materials used. These pieces of evidence probably suggest that the CS professors are searching and using digital to support their classes in different approaches, attending different student profiles. Professors who use digital resources (like OER) seem to be concerned with issues such as the quality and credibility of the material and the authors. For this reason, they usually opt for videos and scientific materials. This trend may be due these types of resources provide greater credibility to students and the professor themselves. For example, a video or course is usually developed by professionals who have a thorough knowledge of the topic, similar to scientific papers, which have a peer review.

\subsubsection{Summary and Findings of the Strategies}

Based on the summary of strategies previously presented, we highlight the following findings: 


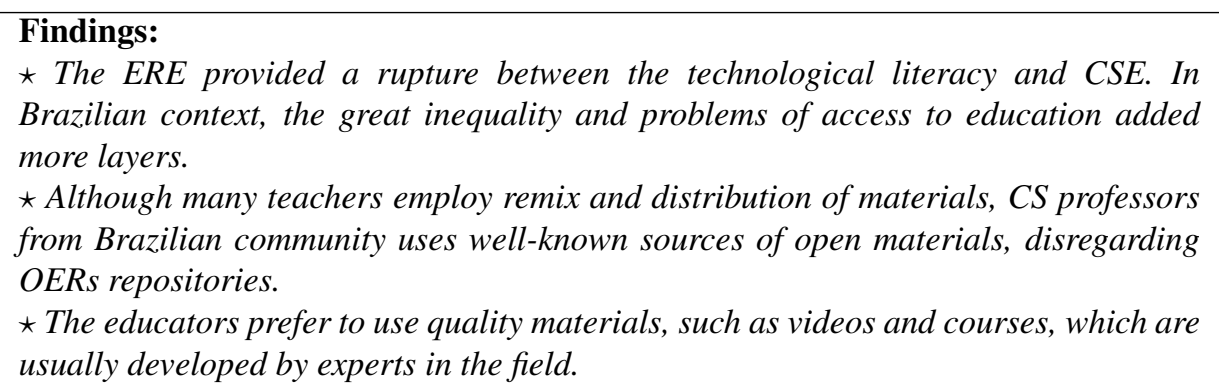

\section{Discussion}

In order to answer the research question posed in the beginning of the study, namely how has ERE been conducted by CS professors in Brazil?, we considered the aspects mapped in previous sections. In summary, we identified a rupture between CSE was conducted before the pandemic and how it is now with ERE. Below, we present a synthesis based on the results obtained.

First of all, the main problem is related to the lack of pedagogical strategy. As previously discussed by Franco (2016), the educator must collect learning from sources and incorporate them in their teaching process, considering what is necessary for the student's pedagogical moment. Thus, the teaching and learning is a systematic and organized process using materials, classes, and student support. However, in our survey, we identified a lack of pedagogical strategy in Brazilian context considering CS educators. As presented, often these professionals didn't have time and schedule to adapt their teaching materials. In addition, these adaptation was performed by professors without previous experience in remote learning. Remembering, ERE is not like face-to-face or distance learning, but the experience with recording video-classes and preparing exercises/assessments can help professionals at this time. However, as we have presented, most of CS educators are having the first experience with this modality. Based on the responses gathered, the professors noticed a greater impact on the interaction with students, on the evaluation process and on activities than on recording the classes.

Many authors have presented ICTs as a solution for integration into pedagogical practices. In this context, the ERE would be a window of opportunity to achieve such integration. According to the responses of our survey, educators are using different tools. Although we have reached an average of 3 tools per participant, it is likely that there are even more tools not mapped by the participants themselves. However, we emphasize that the insertion of these tools not follow a systematic action. In fact, while there are ICTs that support aspects of teaching and learning (such as exercise correction and engagement), many of them were not designed for teaching, e.g., web conferences and video platforms. In short, those are adaptations for education. In this context, these tools were not designed considering students' and professors' perspective. Thus, as commented by Joye, Moreira, and Rocha (2020), this may imply the misuse of its strengths and weaknesses, as well as its impacts on teaching and learning.

Commonly CS professors apply traditional classes to teach CS topics, presenting the content and applying evaluative activities. But, how to do this remotely? And, as already mentioned, without previous experience in this modality of teaching? From the responses, we identified these teaching strategies were rethought due to problems of lack of face-to-face classes and socioeconomic issues. Initially, CS professors and educational institutions were trying achieve 
the best result possible considering these conditions. However, some domains of CS can add more layers of difficulties for emergency education. For instance, programming courses that involve setting up work environments (such as installing programming software) can impose difficulties for students and professors. In educational institutions, there are almost always labs with configured computers for the classes. Nonetheless, this does not happen with personal computers, in which the installation of new software is subject to problems/errors and may not have the required configuration to properly run the necessary software. Also, in Brazil, the social inequality seems to have become even more evident with emergency education. Students (or professors) who do not have an internet connection, computers or smartphones, needed to adapt in an emergency manner. We noticed individual efforts to avoid this difficulty by providing audio or print classes. However, the distribution of this material is not yet evident as it happens, and it does not seem to be a systematic practice, but it can certainly be considered as the only strategy to teach classes at this critical moment for many students.

At same time, participants are searching the web for videos (video lessons, videos from others professors and videos about the theme) to their students. Also, teaching materials, digital books, exercises, projects and homework also received lots of attention. Based on the responses, the educators are retrieving these resources from well-known sources (e.g., YouTube and Digital Libraries). However, commonly these resources are stored in OER repositories. In addition, OERs for CS community is a tendency with many repositories and collections dedicated to providing materials to educators and students in different domains of CS (Tovar et al., 2017; Combefis et al., 2019).

We also highlight specific aspects of CS ERE in Brazil. Initially, there is an interesting debate as to whether emergency education is, in fact, positive or not. The decision to continue classes was seen by many professors as an arbitrary action that further increases inequality problems that already exists in the country. This is a picture in the opinion of many professors who participated in the survey and had to teach their classes on an emergency mode, especially in poorer regions. However, other professors believe this was a correct decision, reinventing teaching (and the way of teaching). Next, the type of institutions also reveals interesting aspects of the analysis. A private institution, for instance, in which most students pay tuition fees, does not present as many infrastructure challenges for professors. In these cases, the institutions seem to be able to provide materials for students and professionals who needed to adapt. This, however, is not the absolute reality of public institutions, especially those located in regions with poor socioeconomic indicators. In this case, the institutions are unable to provide both students and professors the necessary infrastructure. Also, there is an absence of public power to guide the ERE strategy. The vacuum created by this is being filled by the individual actions of teachers and also by the educational institutions. In this sense, we highlight the adoption of tools used in remote education that do not clearly disclose what information is collected, leading to privacy issues.

In Brazil, one of the main causes of these problems - besides the pandemic itself - is the lack of crisis management by political entities. Based on Arruda (2020), many mismatched actions were taken. It is still echoes today in backward schedules, loss performance of student and teachers fatigue. In this context, currently there are two situations of ERE: (i) CS professors that worked in the first term without any preparation or planning; and (ii) CS professors who have had their calendars suspended and will start their remote classes in the second term (or later), and for this reason they had time to organize or have prior preparation. In both cases, questions, 
problems and challenges have emerged. We highlight the reports of professors who taught classes in the first term arguing about the difficulty of participating. There have been many reports that participation in classes is extremely low, and often only students who participate in face-to-face classes participate in remote classes. This can demotivate professors who have not tried remote classes yet.

\subsection{Open Questions}

During the study, participants sent comments on their experience with ERE. We systematized the main topics that can be further investigated in new studies and discussions for the area. Among them, we highlight the following:

- Can public, private and community education achieve different results? We identified different realities among professors from their institutions. For instance, one participant reported that the private university in which he/she works had great support in the distribution of materials (such as notebook and internet) to all students who did not have such equipment and there was already a preparation of the active teaching methodology since 2018. Thus, the ERE has been such an "excellent experience". Professors from public universities, however, seem to face a much more difficult scenario. In this sense, we captured reports of lack of equipment (especially notebooks and internet) for students as systemic problem, occurring mainly in educational institutions located in poorer regions. In addition, there are also community institutions, which apparently can achieve different results and problems considering their vocation as a community. Thus, new research emerges, which is to compare the challenges and results achieved by each type of institution.

- Emergency education is a good or bad solution? Although we have not investigated whether ERE can be a positive or negative alternative for students and professors, we have received feedback saying that the experience has been different for many professors. On the one hand, for instance, two participants pointed out that "the receptivity of the students was very good. It represented a way to keep the brain in motion during the quarantine period" and "for me it was a surprise that it improved very badly I have performance and synergy between the members from the team". On the other hand, we identified a comment saying "[The ERE is] too bad, because students lack feedback during classes. Many of them disperse and get lost in the course". Also, another professor said that "[during the ERE] teachers dedicate time and effort in preparing classes, adapting to a new way of working, which does not work well and accentuates inequalities, instead of working to help to fight the pandemic". Thus, we suggest further exploratory research to analyze the meaning of the ERE for professors.

- How to teach computing without a computer? There are different courses that involve computing. Some of them may be more intuitive in emergency education, but others are not. One example of this was stated by the participant as "Several [students] do not have internet at home, many do not even have a smartphone to read PDF, perhaps trying to carry out programming activities. Web Design, as the name says, is very visual... It does not make sense for students to be placing HTML tags and creating CSS styles or Javascript Scripts 
on paper!". Then, a challenge emerges, how professors are teaching practical subjects, especially programming, in emergency mode?

- Was there learning? One of the biggest questions at this point is whether students are actually learning. The lack of face-to-face classes also showed difficulties in applying assessments. Although this is not the only mechanism for assessing the students' acquired knowledge, it is certainly one of the most widely used. In this regard, one participant reported: "the big problem with remote education is still the assessment, which, in my view, needs to be in person, or just we will believe that there was learning".

\subsection{Implication of findings}

In the previous sections, we highlighted the main findings provided by this research. Now we summarize the practical and theoretical implications of them.

From the practical perspective, we highlight the systematization made and the findings identified as well as the tools adopted, impacts noted and strategies being used. Thus, we believe that several professors and students can recognized and experienced in this research at least one or more of the points explored. Furthermore, it can guide new professors who still have to face the challenge of teaching in an emergency way how this teaching was practiced by peers. Besides, due to the breadth of responses captured, we believe that an overview of how CS education has been developed by professors from all regions of Brazil has been provided. Even to our knowledge, considering the participation, it is the most extensive research on the subject in the national scenario.

Regarding the research perspective, we believe that understanding the way which CS education is being practiced at this critical moment is a contribution to the area and to researchers who wish to understand the dynamics of ERE, especially in Brazil. The contributions provided can guide further studies on the topic, since as long as the country is under the effects of the quarantine there is no expectation of returning to face-to-face classes. Not at least in 2020, in most institutions. Therefore, education that is currently labeled as emergency and remote may be more common than expected and desired by many.

Lastly, the results presented in this study serve as a picture of the current scenario. We believe that initiatives can arise from the actions taken by professors. For example, new educational channels on video platforms (such as YouTube) may flourish now that diverse material professors. In addition, communities of practice can emerge with the aim of disseminating digital materials for teaching and learning. The exchange of experience about what is working and what is not working can help the CS community.

\section{Threats to validity}

In this section, we provide a summary of the main limitations of our survey.

External Validity: a potential threat in this study refers to the ambiguity and the problems of interpreting the questionnaire among the participants. To prevent this, we conducted a pilot test with participants, and rewrote ambiguous questions. In addition, whenever possible we used 
examples and descriptions to facilitate understanding of the questions. Another external threat concerns the generalization of the results obtained. To mitigate this risk, we collected responses from all regions of Brazil and from institutions that integrate the public and private educational systems. However, in 4 states in the northern region we had no participants (Acre, Rondônia, Tocantins, and Roraima). This threat can be mitigated by the fact that we had participants from this region, coming from the states Amapá, Amazonas and Pará.

Internal Validity: the systematization of the analyzed data presents a potential threat to the internal validity of this study, such as performing the wrong classification of the participants' responses. To mitigate this risk, we analyzed the responses individually and classify them in clusters according to similarity. Also, questions with list of registered options can have add potential bias in responses. In order to prevent the incidence of this risk, the questions that had answering options always had the "Other" field with free edition. The reliability and validity also present potential threats to this investigation. The main threat related to the survey reliability was the verification using the internal consistency mechanism. However, as commented by Wainer (2007), there is no consensus on how to overcome reliability problems in computing surveys. Thus, we used a common and well accepted strategy for computing investigations. Finally, the main validity limitation of this survey was we used only content validity, disregarding others strategies. To solve this, we carried out an evaluation with three specialists from area.

\section{Conclusion}

The main purpose of this investigation was answer the following research question: how has ERE been conducted by CS professors in Brazil? For this, we conducted a survey with 137 educators from 69 educational institutions in 20 Brazilian states and presented the impacts of emergency education as well as the main strategies that have been adopted. Based on the result achieved, we identified that ERE provided a rupture in CSE for professors and students. In short, we noticed a lack of pedagogical strategy due to educators didn't have time/schedule to organize their classes and materials. In addition, many professionals are facing remote learning by first time. As a result the adaption and creation of teaching materials are problematic. Many of problems are the result of the pandemic, but the lack of efficient crisis management by political entities associate to the social inequality, made ERE even more challenging for CS professors in Brazil.

As future work, we highlight the need of understanding the impact that ERE is causing among the CS professors and students. Therefore, we suggest further investigations based on the open questions highlighted in Section 5.1. Furthermore, we also believe that collaborative practices can support emergency teaching, such as the exchange of knowledge among professors that have taught classes in ERE modality with professors that are planning to resume activities.

\section{Acknowledgements}

The authors would like to thank the Brazilian funding agencies - Coordenação de Aperfeiçoamento de Pessoal de Nível Superior - Brasil (CAPES); São Paulo Research Foundation (FAPESP) under grants \#2018/15163-6 and \#2018/26636-2; and CNPq under grant $\# 141010 / 2018-5$. We also thank the professors that took part of the study and the reviewers for their comments. 


\section{References}

Arruda, E. P. (2020). Educação remota emergencial: elementos para políticas públicas na educação brasileira em tempos de Covid-19. EmRede-Revista de Educação a Distância, 7(1), 257-275. [GS Search]

Castaman, A., \& Rodrigues, R. (2020). Distance Education in the COVID crisis - 19: an experience report. Research, Society and Development, 9(6), 180963699. doi: 10.33448/rsd-v9i6.3699 [GS Search]

Ciotti, M., Angeletti, S., Minieri, M., Giovannetti, M., Benvenuto, D., Pascarella, S., . . Ciccozzi, M. (2019). Covid-19 outbreak: an overview. Chemotherapy, 64(5-6), 215-223. doi: 10.1159/000507423 [GS Search]

Combefis, S., Moffarts, G., \& Jovanov, M. (2019, September). Tlcs: A digital library with resources to teach and learn computer science. Olympiads in Informatics, 13, 3-20. doi: 10.15388/ioi.2019.01 [GS Search]

de Mello, R. M., \& Travassos, G. H. (2016). Surveys in software engineering: Identifying representative samples. In Proceedings of the 10th acm/ieee international symposium on empirical software engineering and measurement. New York, NY, USA: Association for Computing Machinery. doi: 10.1145/2961111.2962632 [GS Search]

Dias, R. d. F. R., \& Albano, C. S. (2017). Novas práticas pedagógicas como forma de promover a interdisciplinaridade e mitigar a diversidade. Ensino da Matemática em Debate, 4(2), 106-120. [GS Search]

Espíndola, M. B., Struchiner, M., \& Giannella, T. R. (2010). Integração de tecnologias de informação e comunicação no ensino: Contribuições dos modelos de difusão e adoção de inovações para o campo da tecnologia educacional. RELATEC: Revista Latinoamericana de Tecnología Educativa, 9(1), 89-106. [GS Search]

Ferreira, D. J., Ambrósio, A. P., Nogueira, T., Ullmann, M. R. D., \& Melo, T. F. N. (2018). Students' Perceptions of Applying Real-world Problem Solving in Computer Science Education : Case Study in Interaction Design. In 2018 IEEE Frontiers in Education Conference (FIE) (p. 1-8). doi: 10.1109/FIE.2018.8658458 [GS Search]

Ferreira, M., \& Carneiro, T. C. J. (2015). A institucionalização da educação a distância no ensino superior público brasileiro: análise do Sistema Universidade Aberta do Brasil. Educação Unisinos, 19(2), 228-242. doi: 10.4013/edu.2015.192.07 [GS Search]

Franco, M. A. d. R. S. (2016). Prática pedagógica e docência: um olhar a partir da epistemologia do conceito. Revista Brasileira de Estudos Pedagógicos, 97. doi: 10.1590/s21766681/288236353 [GS Search]

Joye, C., Moreira, M., \& Rocha, S. (2020). Distance Education or Emergency Remote Educational Activity: in search of the missing link of school education in times of COVID-19. Research, Society and Development, 9(7). doi: 10.33448/rsd-v9i7.4299 [GS Search]

Karalis, T. (2020). Planning and Evaluation During Educational Disruption: Lessons Learned from Covid-19 Pandemic for Treatment of Emergencies in Education. European Journal of Education Studies, O(0). doi: 10.5281/zenodo.3789022 [GS Search]

Kitchenham, B., \& Pfleeger, S. L. (2002, May). Principles of survey research part 4: Questionnaire evaluation. SIGSOFT Softw. Eng. Notes, 27(3), 20-23. doi: 10.1145/638574.638580 [GS Search]

Levy, P. (1999). Cibercultura. Editora 34. 
Linåker, J., Sulaman, S. M., Maiani de Mello, R., \& Höst, M. (2015). Guidelines for Conducting Surveys in Software Engineering. Retrieved from https://lup.lub.lu.se/search/ ws/files/6062997/5463412.pdf [GS Search]

Marcolino, A. S., \& Barbosa, E. (2017). A survey on problems related to the teaching of programming in Brazilian educational institutions. In 2017 IEEE Frontiers in Education Conference (FIE) (p. 1-9). doi: 10.1109/FIE.2017.8190495 [GS Search]

McCowan, T. (2007). Expansion without equity: An analysis of current policy on access to higher education in Brazil. Higher education, 53(5), 579-598. doi: 10.1007/s10734-005-0097-4 [GS Search]

Medio, C. D., Limongelli, C., Sciarrone, F., \& Temperini, M. (2020). MoodleREC: A recommendation system for creating courses using the moodle e-learning platform. Computers in Human Behavior, 104, 106-168. doi: 10.1016/j.chb.2019.106168 [GS Search]

Novoa, A. (1992). Formação de professores e profissão docente. Lisboa: Dom Quixote, 13-33. Retrieved from http://hdl.handle.net/10451/4758 [Book chapter.]

Oliveira, A. W., Schneider, E., \& Kim, Y. (2020, Jul). Curriculum conceptions of technology: Theoretical insights from National Education Policies in Brazil, Korea, and the United States. Human Behavior and Emerging Technologies, n/a(n/a), 1-10. doi: 10.1002/hbe2.204 [Special Issue Article]

Paschoal, L. N., \& de Souza, S. d. R. S. (2018). A Survey on Software Testing Education in Brazil. In Proceedings of the 17th brazilian symposium on software quality (p. 334-343). New York, NY, USA: Association for Computing Machinery. doi: 10.1145/3275245.3275289 [GS Search]

Sohrabi, C., Alsafi, Z., O’Neill, N., Khan, M., Kerwan, A., Al-Jabir, A., ... Agha, R. (2020). World Health Organization declares global emergency: A review of the 2019 novel coronavirus (COVID-19). International Journal of Surgery, 76, 71 - 76. doi: 10.1016/j.ijsu.2020.02.034 [GS Search]

Tovar, E., Chan, H., \& Reisman, S. (2017, July). Promoting MERLOT Communities Based on OERs in Computer Science and Information Systems. In Annual Computer Software and Applications Conference (COMPSAC) (Vol. 2, p. 700-706). doi: 10.1109/COMPSAC.2017.290 [GS Search]

Triyason, T., Tassanaviboon, A., \& Kanthamanon, P. (2020). Hybrid Classroom: Designing for the New Normal after COVID-19 Pandemic. In Proceedings of the 11th International Conference on Advances in Information Technology. New York, NY, USA: Association for Computing Machinery. doi: 10.1145/3406601.3406635 [GS Search]

Wainer, J. (2007). Métodos de pesquisa quantitativa e qualitativa para a ciência da computação (Vol. 1). Sociedade Brasileira de Computação/Editora PUC Rio Rio de Janeiro.

Wiley, D. (2014). The Access Compromise and the 5th R. Open Content Blog. Retrieved from https://opencontent.org/blog/archives/3221

Zhang, W., Wang, Y., Yang, L., \& Wang, C. (2020, March). Suspending Classes Without Stopping Learning: China's Education Emergency Management Policy in the COVID-19 Outbreak. Journal of Risk and Financial Management, 13(3), 55. doi: 10.3390/jrfm13030055 [GS Search] 